\title{
The effects of Task-Based Language Teaching on the Speaking Skill: A systematic research synthesis and meta-analysis.
}

Los efectos del método de enseñanza de idiomas basado en tareas en la habilidad oral: Una síntesis de investigación sistemática y meta análisis.

\author{
Alberto Medina Fernández. ${ }^{1}$
}

Recibido: 12-08-2021 / Revisado: 22-08-2021 /Aceptado: 09-09-2021/ Publicado: 05-10-2021

\begin{abstract}
DOI: https://doi.org/10.33262/cienciadigital.v5i4.1801

Introduction. For more than three decades Task-based language teaching strategies have constituted an object of research in second language acquisition. However, a TBLT approach has been fully embraced in some parts of the world while not in others. Despite the fact that there have been previous systematic reviews and meta-analyses investigating TBLT implementation, there is still the need for a synthesis of the effects of tasks on oral production. Objective. The study aims to estimate the effects of TBLT implementation on the speaking skill development holistically and through the components of complexity, accuracy and fluency. Methodology. This paper provides a systematic research synthesis of different TBLT interventions on spoken production. In total, 61 published studies were retrieved, coded, and analyzed following established coding procedures for systematic reviews. Additionally, 11 studies were also meta-analyzed so as to research the overall effects of the application of a TBLT speaking strategy as treatment in different contexts. Results. The findings unveiled a medium to large effect of $(d=0.78)$ for TBLT interventions on oral production. The synthesis across qualitative and quantitative data also revealed a positive impact of Task Repetition and Pre-task planning for the

\footnotetext{
${ }^{1}$ Pontificia Universidad Católica del Ecuador - Sede Ambato: Ambato, Tungurahua, EC,Maestría en Pedagogía del Inglés como Lengua Extranjera, Ambato, Ecuador, email: alberto.medina.f@ pucesa.edu.ec, https://orcid.org/0000-0002-4291-720X
} 
enhancement of linguistic complexity, accuracy and fluency dimensions of the speaking skill. Conclusion. The study concludes with implications for the implementation of a TBLT strategy in L2 teaching-learning process. It is evidenced that a TBLT strategy offers improvement possibilities for the development of the speaking skills in intermediate level students.

Keywords: TBLT, Pedagogical Task, Speaking Skill, Spoken Interaction

\section{Resumen}

Introducción. Durante más de tres décadas, las estrategias de enseñanza de lenguas basadas en tareas han constituido un objeto de investigación en la adquisición de segundas lenguas. Sin embargo, un enfoque TBLT se ha adoptado plenamente en algunas partes del mundo, pero no en otras. A pesar de que ha habido revisiones sistemáticas y metanálisis previos que investigan la implementación de TBLT, todavía existe la necesidad de una síntesis de los efectos de las tareas en la producción oral. Objetivo. El estudio tiene como objetivo estimar los efectos de la implementación de TBLT en el desarrollo de la habilidad de hablar de manera integral y a través de los componentes de complejidad, precisión y fluidez. Metodología. Este artículo proporciona una síntesis de investigación sistemática de diferentes intervenciones TBLT sobre la producción hablada. En total, se recuperaron, codificaron y analizaron 61 estudios publicados siguiendo los procedimientos de codificación establecidos para las revisiones sistemáticas. Además, también se realizaron metanálisis de 11 estudios para investigar los efectos generales de la aplicación de una estrategia de habla TBLT como tratamiento en diferentes contextos. Resultados. Los hallazgos revelaron un efecto de medio a grande de $(\mathrm{d}=0,78)$ para las intervenciones de TBLT en la producción oral. La síntesis de datos cualitativos y cuantitativos también reveló un impacto positivo de la repetición de tareas y la planificación previa a la tarea para mejorar la complejidad lingüística, la precisión y las dimensiones de fluidez de la habilidad de hablar. Conclusión. El estudio concluye con implicaciones para la implementación de una estrategia TBLT en el proceso de enseñanza-aprendizaje de lenguas extranjeras. Se evidencia que una estrategia TBLT ofrece posibilidades de mejora para el desarrollo de la habilidad oral en estudiantes de nivel intermedio.

Palabras clave: TBLT, Tarea pedagógica, Habilidad oral, Interacción oral.

\section{Introduction}

\section{Task-based Language Teaching rationale}

TBLT methodology has been applied in different parts of the world as an alternative to other traditional methods for the development of communicative competence. As Ellis \& Shintani (2014) put it, TBLT aims at engaging students in meaning-focused communication through the performance of tasks. It is based on providing opportunities for learners to focus not only on language but also on the learning process itself (Nunan, 
2004). While learners do the tasks they interact in the target language to reach a preestablished outcome. Generally, the kind of tasks used in TBLT tends to link classroom language learning with language use outside the classroom (Nunan, 2004). Ever since the advent of the communicative approach to second or foreign language teaching, language educators and policy-makers have attempted to devise new ways of teaching oral production in language courses in more productive and meaningful ways. One of these proposals was Task-based language teaching which has been extensively researched throughout the last 30 years as an approach that attempted to increase students' involvement in more meaningful, real-world and as part of form-function relationship in language acquisition (Van den Braden, 2006). Thus, there persists the need to synthesize the current available research and corroborate the advantages and limitations of TBLT practices and potentialities for Second or Foreign Language Oral Production enhancement. The present study represents a synthesis of the body of work that takes into account the impact of TBLT interventions in the acquisition and development of speaking skills in Second Language and Foreign language learners.

\section{Tasks as the driver of the teaching-learning process}

In TBLT, real-world tasks become pedagogical tasks that resemble communication in the real world. However, to define tasks, one of the most important aspects to take into account is that, as Richards \& Rodgers (2001) stated, tasks do not necessarily involve the production of language since they further the processes of meaning negotiation, modification, and experimentation. Therefore, tasks can be oriented towards comprehensible input and to the production of language while emphasizing meaning exchange. In essence, pedagogical tasks are classroom pieces of work that engage the learners in comprehension, manipulation, and interaction; or language production while mobilizing their grammatical knowledge to express meaning (Nunan, 2004). While carrying out tasks, learners are free to use different grammatical structures and linguistic resources previously acquired, to achieve an outcome.

\section{Framework for TBLT and task types}

At a syllabus level, tasks must be linked together through 'task chaining' (Nunan, 2004). This means that they are organized according to units of work, and at a unit level, in terms of functions, grammar and lexis that are expressed through them.

In a task-based lesson, the general agreed on phases that have been proposed are pre-task (can be seen as a planning phase), main task (performing the task in groups), and post Task or Language Focus phase (a focus on reporting language, and extra language work needed).

As stated earlier, the types of tasks in TBLT are those that resemble what people do with language in the real world. Pedagogical tasks have been classified according to different criteria and aims. Thus, tasks can have a rehearsal rationale or an activation rationale. They can be sorted in terms of the operations required, such as listing, ordering, comparing, problem-solving, sharing information, or creation. Besides, tasks could 
include an information gap, an opinion gap, or a reasoning gap as defined by Prabhu, N.S. (1987). These represent the most frequent tasks for the development of speaking skills, which will be analyzed in this work.

\section{Focus on form in tasks}

A much-debated topic on TBLT research and application has been whether communicative tasks employed in a task-based approach neglect a focus on linguistic forms. While an explicit focus on form in tasks is not a feature of strong versions of TBLT, early versions of task cycles included a focus on grammatical forms in the pretask phase. More recently, a combination of focus on form and expression of meaning has been incorporated in the task cycles utilizing recasts and prompts that offered the learners a more effective control of forms while expressing themselves.

\section{Methodology}

The current study followed a bibliographical design characteristic of systematic reviews and meta-analysis which includes the search and selection of studies according to a set of criteria. The particular method chosen for this study was mixed research synthesis due to the nature of the research questions aimed at exploring the most common effects and practices, as well as the prevalence of pretest-experimental-posttest designs, generally used in TBLT research. Thus, it required a mixed-method synthetic approach for the integration of the findings of several published qualitative, quantitative and mixed primary level articles (Heyvaert, M. et al., 2011).

\section{Search keywords}

At the beginning of this research synthesis, keywords related to TBLT and the SPEAKING SKILL were established as:

(TASK-BASED LANGUAGE TEACHING / PEDAGOGICAL TASKS/ COMMUNICATIVE TASKS / SPEAKING SKILLS /SPOKEN INTERACTION/ FLUENCY/ PRONUNCIATION/ L2 ORAL PRODUCTION)

To conduct a thorough search, the following combinations were used to retrieve reports about the intended research questions:

Combinations used:

["TASK-BASED LANGUAGE TEACHING"] + [“COMMUNICATIVE TASKS"] + ["PEDAGOGICAL TASKS"] + ["SPEAKING SKILLS"] + ["SPOKEN INTERACTION"] + ["FLUENCY"] + ["PRONUNCIATION"] + ["L2 ORAL PRODUCTION']

\section{Data sources:}

Firstly, an initial search was conducted using the search keywords through combinations on the following databases and journals: 
DATABASES:

1- ERIC

2- SCIENCEDIRECT

3- MICROSOFT ACADEMIC

Additionally, searches were carried out in GOOGLE SCHOLAR, and the following journals:

\section{JOURNALS}

- Applied Linguistics • Advances in Language and Literary Studies • ELT Journal • English Language Teaching - International Journal of Applied Linguistics • Journal of English as an International Language $\bullet$ Language Teaching Research $\bullet$ Modern Language Learning $\bullet$ Sage Journal $\bullet$ TESOL Quarterly • The Language Learning Journal.

It was searched on articles' abstracts, titles, and keywords. The literature search was conducted on referred journals that focus on SLA research and were only peer-reviewed journals.

It resulted in 172 articles.

\section{Inclusion and exclusion criteria}

This section gives an account of the procedure and steps taken to search for the published literature pertinent to this research synthesis. It also describes the inclusion criteria used to filter out documents that did not pertain to the object of this systematic review or did not provide relevant data for the research questions proposed. As a second step, the retrieved documents were sifted through a set of pre-established criteria for their inclusion or exclusion. As the last step, studies were evaluated according to the research questions posed previously. The documents selected had to satisfy the eligibility criteria as follows:

1) the study was mainly about developing speaking and L2 oral production within TBLT frameworks.

2) all studies were dated from a 15-year-span, from 2006 to 2021, due to an increase of interest in task-based language teaching research publications.

3) all studies had an intervention on the speaking skills as a whole, or one or more of its aspects such as fluency, interaction, comprehension, accuracy, input or output constructs.

\section{Inclusion and exclusion process}

As previously stated, the queries led to a total pool of 172 articles that matched the selection criteria and resulted from the keyword combinations. This number was then reduced by the following elimination procedure:

Phase 1: elimination based on duplication of titles from various sources which reduced the number from 172 to 141 .

Phase 2: after examining titles and abstracts, a reduction from 141 to 122. 
Phase 3: elimination based on the reports after reading the text, from 122 to 61 . At this phase, reports were excluded on the basis of the directions, quality, and interventions.

The flow of the elimination procedure for screening the articles is represented in Figure 1.

Figure 1

PRISMA flowchart for article inclusion.

Identification of studies via databases and registers

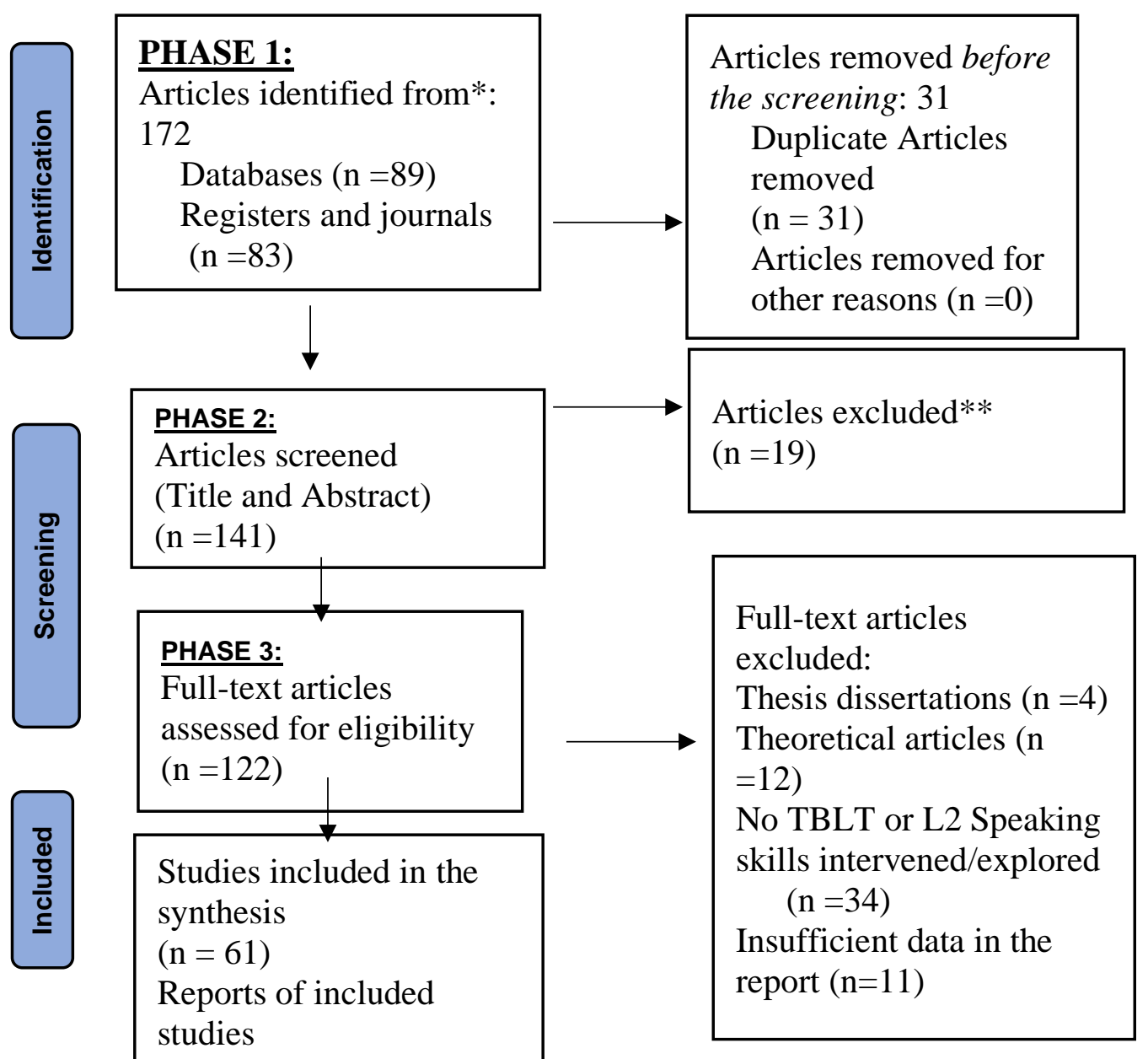

Source: Page, M.J. et al. (2020). The PRISMA 2020 statement: an updated guideline for reporting systematic reviews.

Developed by: The author

\section{Coding the data from reports}

For the analysis-synthesis process of the included reports, a coding scheme was developed to classify the studies according to their substantive and methodological features. It was used to organize the data relevant to the research questions proposed and includes the features that appear in Table 1. 
Table 1

Coding Procedure

\begin{tabular}{|c|c|}
\hline Variable & Operationalization \\
\hline Publication Characteristics: & Name of author(s), Title of publication \\
\hline Author, Title, Journal & Journal name and features \\
\hline \multicolumn{2}{|l|}{ Design Characteristics: } \\
\hline Setting & Foreign or Second Language \\
\hline Institution Type & $\begin{array}{c}\text { Elementary, High school, University, } \\
\text { Institute }\end{array}$ \\
\hline Country & $\begin{array}{c}\text { The country where the intervention took } \\
\text { place }\end{array}$ \\
\hline TBLT Program & $\begin{array}{c}\text { The presence or absence of a TBLT } \\
\text { syllabus }\end{array}$ \\
\hline Duration & $\begin{array}{l}\text { Length of treatment in hours (total class } \\
\text { time) }\end{array}$ \\
\hline Modality & $\begin{array}{l}\text { Face-to-face, multimedia, online or } \\
\text { multiple }\end{array}$ \\
\hline
\end{tabular}

\section{Participant Characteristics:}

Participants L1

Participants L2

Proficiency level
First language of the participants

Target Language

Beginner, intermediate, advanced, multiple

\begin{tabular}{cc}
\hline Methodology: & \\
\hline Research Design & Experimental, quasi-experimental, \\
qualitative, , mixed-method. & TBLT intervention \\
Dependent Variable(s) & Speaking skill dimensions \\
Outcome Variable(s) & CAF measures, Oral Production \\
Speaking skill measures & measurements \\
Pre-test & Inclusion of a pre-test \\
Delayed post-test & Inclusion of a delayed posttest \\
Instrument reliability & Reliability reported for outcome measure \\
instrument & Type of statistical tests \\
Effect size & Effect sizes reported, or sufficient data \\
Findings & for calculation \\
Study Limitations & Interpretation of results \\
\hline
\end{tabular}

Source: Coding categories for research synthesis and meta-analysis. (Norris \& Ortega, 2006)

Developed by: The author 
This type of coding allowed for the retrieval of both qualitative and quantitative information to be synthesized. The kinds of interventions more frequently used by researchers are described in Table 2.

\section{Analysis}

In general, the most commonly used independent variables for oral production emerging from the analysis are TBLT Framework and Holistic Strategy, Task repetition, Pre-task planning conditions, Task sequences, Focus on form, Mobile, and Web-supported TBLT.

\section{Table 2}

TBLT types of interventions in the included studies

\begin{tabular}{cc}
\hline Intervention type & No. of studies \\
\hline TBLT Holistic Strategy & 21 \\
Task Repetition & 10 \\
Task Planning & 8 \\
Task Types & 7 \\
Task Complexity & 4 \\
ICT-supported TBLT & 3 \\
Task Sequence & 2 \\
Pre-task Modelling & 2 \\
Task Rehearsal & 2 \\
ACCESS & 1 \\
Scaffolding & 1 \\
& $\mathrm{~T}=61$
\end{tabular}

Source: Number of studies reviewed by intervention

Developed by: The author

\section{The Quantitative Meta-analysis}

After the application of the coding scheme to the included articles, 11 studies were selected for meta-analysis. These studies were chosen based on the presence of an experimental or quasi-experimental pre-posttest design, as well as having TBLT holistic strategy as a treatment for the experimental group, versus other methodological strategies or teaching methods for the control group. Coded studies that had a descriptive or correlational design were not included. Furthermore, if studies had TBLT types of intervention on both experimental and control groups, they were also not included in the analysis of effect sizes. For the effects of treatment and changes between pretest and posttest, Cohen's $d$ formula was used with a $95 \%$ confidence interval. A correction factor was employed for samples smaller than 50 participants, Hedges, L.V. (1981): 


$$
d=\frac{M_{E}-M_{C}}{\text { Sample } S D \text { pooled }} \times \frac{\left(\frac{N-3}{N-2.25}\right) \times \sqrt{\frac{N-2}{N}}}{\begin{array}{l}
\text { correction factor for } \\
\text { small samples }<50
\end{array}}
$$

\section{Theoretical Framework}

Development of the components and dimensions of the skill of speaking in an ESL or EFL teaching-learning process.

One of the most recurrent concerns in the SLA or FL teaching-learning process has been to develop speaking skills in the learners. As a result, there has been a shift towards approaches and methods that focus on the process of developing this skill, such as CLT and TBLT. To develop this skill effectively, its different components must be analyzed since they constitute the subject matter of most SLA/FL courses. In fact, the components of speaking have been extensively researched by TBLT practitioners and researchers all over the world to determine the effectiveness of communicative tasks previously applied. Therefore, it is necessary to determine the theoretical underpinnings of the speaking skill and their significance in TBLT empirical studies. To do so, it is paramount to ponder on the dimensions of complexity, accuracy, and fluency which have been frequently operationalized as the CAF triad in applied linguistics research (Housen et al. 2012). As well as, the particularities of negotiation of meaning, interaction, and output which are aspects that researchers have systematically paid attention to.

\section{Comprehensible input}

For learners to be able to speak and communicate effectively in L2 there must be tasks that are geared towards comprehensible input in the first place. A speaker must understand first what is being said in order to engage in verbal exchanges effectively. According to Pica et al. (1987), all learners in the second language classroom should participate in interaction and ask questions in order to clarify input. In a sense, language input must precede output. Language input can be oriented towards content, or it can be oriented towards linguistic forms.

\section{Complexity}

The notion of complexity has been defined by several authors and researchers in applied linguistics. In general terms, complexity has been understood as features of language that are particularly difficult for learners to make use of. For the purpose of this synthesis and for overall L2 performance analysis, complexity can best be defined as comprising three components: propositional complexity, discourse interactional complexity, and linguistic complexity (Housen et al. 2012). Where propositional complexity refers to the number of idea units that a speaker processes in a task. Discourse interactional complexity is the number and types of interactional moves that a learner takes. And finally, linguistic 
complexity, which has been defined as the complexity in terms of lexical, morphological, syntactic, and phonological features used by learners (Housen et al. 2012).

\section{Accuracy}

Since the 1980s, researchers have tried to make a distinction between fluent and accurate language usage to investigate L2 oral proficiency (Housen and Kuiken 2009). What is referred to as accurate language production was expressed in terms of error-free language output measured against a model, often that of the native language speaker. Nonetheless, in a CAF triad model, accuracy must also be operationalized in terms of how appropriate and acceptable the language produced is (Housen et al. 2012).

\section{Fluency}

Fluency is one of the most important aspects of speaking because being a fluent speaker of L2 has been equated to being a proficient language user. In other words, fluent speakers respond quickly and accurately in spoken interactions. Therefore, some command over a combination of linguistic forms and communicative functions is needed for the achievement of fluency. The type of effective tasks in TBLT should include some kind of focus on the aforementioned aspects. The measurement of fluency in speaking has to do with the phonological features expressed, such as the rate of speech, amount of pauses, and repetitions of the speaker while engaging in interactions (Housen et al. 2012).

\section{Interaction, output, and negotiation of meaning.}

The role of interaction, output, and negotiation of meaning has become one of the integral parts of the speaking skill. In tasks or activities where students converse or exchange meaning towards reaching a certain outcome, these components are present. Traditionally, the methods under the communicative approach have been devised for the treatment of these three aspects. Conversational skills constitute a key part of the performance of TBLT task cycles. Besides, learners need to understand the social context, roles, and language functions they express. In the same way, there must be a communicative output that fulfills the communicative objectives of tasks. As learners get involved in meaning exchange to reach a common aim, conversational strategies are to be developed in the learners in a way that fosters the formation and use of these speaking skills. As previously stated, the dimensions of complexity, accuracy, and fluency comprise the linguistic and functional aspects that have been the object of research in TBLT interventions to develop speaking skills in L2 programs. They have been defined as the constructs that measure the extent to which any pedagogical intervention can be regarded as effective or less effective in the appraisal of spoken production. It has been upon that basis that the current synthesis has been motivated. Ultimately, the motivation has been to take stock of the current research that measures the extent to which TBLT methodology and its pedagogical tasks influence the aforementioned constructs of the speaking skill in the learners. Therefore, the following research questions guide this study: 
Research question 1: What are the benefits and limitations of the implementation of pedagogical task frameworks in the development of spoken production constructs in terms of (a)complexity, (b) accuracy, (c) fluency, and (d) spoken interaction in these studies?

Research question 2: Overall, how effective is a TBLT strategy for the development of the speaking skill for L2 learners in classroom environments?

For the investigation of the above questions, studies were categorized according to the type of TBLT framework, Task intervention and their overall effects on oral production components.

\section{Results}

\section{The research synthesis}

This section gives a broad account of the synthesis of the publications, participants, and types of interventions used; as well as their effects on the different speaking constructs and dimensions. The aim is to provide a wider view on the impact of the treatments for complexity, accuracy, fluency plus conversational skills, and negotiation of meaning dimensions.

Publications. The totality of studies collected was varied in research design and objectives. Studies were classified into 3 subsets as follows: studies that had TBLT tasks manipulations as independent variables and syntactic complexity, accuracy, lexis and fluency measures (CALF) as dependent variables $(n=38)$, qualitative method studies $(\mathrm{n}=2)$; and between-group studies that compared TBLT strategy implementation in the experimental group versus other teaching methods in the control group $(n=21)$. Out of 61 experimental studies published from 2006 to 2021, 11 studies met the previously mentioned criteria for inclusion in the meta-analysis.

\section{Research designs and settings}

The majority of studies used a between-groups quasi-experimental design. Only $20 \%$ of studies used a mixed-method design with the inclusion of qualitative techniques such as questionnaires and interviews. Treatment tasks included roleplays, information-gap, opinion gaps, decision making, problem-solving, and oral narrative tasks. The age of participants in the studies ranged from 15 to 58 with the exception of one study where participants were 9-11-year-olds. The most frequent L1s reported were Arabic, Chinese, Korean, Japanese, and Indonesian because of an increased research and implementation of TBLT in the Asian-South pacific region. The target language contexts consisted of English as a Foreign Language (90\%), English as a Second Language (8\%), French as a Foreign Language (1\%), German as a Foreign Language (1\%). The level of proficiency of participants was the following in studies percentage: beginner level (26\%), preintermediate level (19\%), intermediate level (53\%), advanced level (2\%).

\section{Statistical Analysis}


The statistical data reported was varied and in some instances inconsistent. In total, $(\mathrm{n}=53)$ studies reported statistical analyses. The following tests were employed: independent t-tests (34\%), paired samples t-test (24\%), one-way ANOVA (13\%), repeated-measures ANOVA (11\%), MANOVA (10\%), Pearson Test for correlation (4\%), Wilcoxon signed ranks test (2\%), and Mann-Whitney U-test (2\%).

\section{Effectiveness of TBLT interventions on oral production}

\section{Outcome measures used for complexity, accuracy and fluency}

The 38 studies that had complexity, accuracy and, or fluency as dependable variables used similar measures in their operationalization. Complexity measures included the ratio of clauses to AS-units (the Analysis of Speech Units), the number of complex AS-units. Fluency was measured as speech rate (number of syllables per minutes). Accuracy measures included: (Errors per 100 words), Percentage of error-free clauses.

\section{Task types and Task Variation Interventions on Complexity, Accuracy and Fluency.}

For measures of the CAF triad, the most recurring interventions used in 35 studies have been; variations in the procedures for Task Repetition, Task Planning, Task complexity, and Task Types. In regards to Task Types, the ones used to intervene for measures of complexity, accuracy, and fluency have been decision-making tasks, information-gap tasks, dialogic and monologic narrative tasks, and picture-based description tasks. The studies that used task repetition as an independent variable have evidenced gains for accuracy, complexity, and more discretely for fluency. However, in one particular study where "massed repetitions" of the same task occurred 11 times over a sixth-month period, statistically significant differences between the experimental and control groups on all the posttest measures for complexity and fluency were obtained (Ahmadian, J., 2011). Other studies using task repetition have been based on Bygate and Samuda (2005)'s arguments about the role of task repetition in allowing L2 learners to pay attention to both meaning and form in task execution, and thus, the consolidation of language acquired. In these cases, task repetition has been found to aid learners to produce more task-induced linguistic features and gains in complexity measures in the subsequent repetitions. Furthermore, identical task repetition was found in one study to raise L2 learners' gains in accuracy by Gashan \& Almohaisen (2014).

Some other studies have paid attention to task planning conditions, task complexity, and task structure to measure its impact on the CAF dimensions. In this case, it has been found that the most significant gains have appeared in fluency and accuracy dimensions. In broad terms, it has been inferred from the studies' results that a more structured and planned task sequence yields better results for complexity and fluency, and a little less evident for accuracy gains. Based on the Trade-off hypothesis (Skehan, 2009), and Levelt's (1989) model of speech production, the studies used online planning, strategic planning, pre-task planning and planning conditions (pressured vs. unpressured, individual vs. collaborative) as independent variables. According to data form the studies, it can be interpreted that online planning, where students are given ample time to plan 
their speech, aided their performance in terms of complexity and accuracy. Strategic planning (allowing learners an amount of time to plan), and pre-task planning strategies improved learner's fluency and linguistic resources due to opportunities to conceive and perfect messages before performing the actual tasks.

On the other hand, precise findings on task types used in these studies indicate that the use of picture-based description and narration tasks increased the speed of speech production. Spot-the-difference tasks, had a significant impact on accuracy improvement. Decision-making tasks were regarded as more conducive to greater complexity while information-gap tasks had more effects on fluency development.

\section{Accuracy treatments in TBLT frameworks for Speaking Tasks and generation of LREs (Language Related Episodes)}

One of the aspects of the TBLT approach that has received more attention from critics is attention to form within a task-based framework or lesson. For the case of oral production and interaction, researchers in the studies included in the current synthesis analyzed the occurrence of LREs during task interventions such as task repetition, task rehearsal, pretask planning, and ACCESS. With the inception of ACCESS, students generated more grammatical LREs because this intervention is based on the repetition of sets of utterances and expressions (Dao, P. et al 2016). Some other studies explored the influence of task repetition, task rehearsal, and task complexity on form-focus and LREs generation. In sum, it can be stated that task repetition favors the appearance of self-corrections and more use of L2 language during task performance. Interventional studies for accuracy measures are represented in table 3 . In addition, both pre-task instruction and task complexity seem to stimulate the production of more lexical LREs and accurate speech production in terms of linguistic forms retrieved.

\section{Table 3}

Accuracy focus in Intervention Treatments

\begin{tabular}{cccccc}
\hline Study Tests & Sample & Intervention & Focus & Measures & Stat \\
\hline $\begin{array}{c}\text { Dao, P. et al. } \\
(2016)\end{array}$ & 33 & ACCESS & LREs & Number of LREs & - \\
$\begin{array}{c}\text { Hawkes, M. } \\
(2011)\end{array}$ & 60 & $\begin{array}{c}\text { Post-task } \\
\text { (Task } \\
\text { repetition) }\end{array}$ & Vocabulary & Conv. Analysis & - \\
Kim, Y. (2012) & 45 & $\begin{array}{c}\text { Pre-task } \\
\text { Modelling }\end{array}$ & Questions & Oral Tests & Wilcoxon \\
Park, S. (2010) & 110 & $\begin{array}{c}\text { Pre-task } \\
\text { Planning }\end{array}$ & LREs & Number of LREs & ANOVA \\
Salimi, A. (2015) & 60 & $\begin{array}{c}\text { Task } \\
\text { Complexity }\end{array}$ & Accuracy & CAF measures & ANOVA \\
Nguyen, T. (2019) & 48 & Task Rehearsal & LREs & Number of LREs & ANOVA \\
\hline
\end{tabular}

Source: Reviewed studies focusing on accuracy measurements

Developed by: The author 
TBLT effectiveness on spoken interaction, negotiation of meaning, and linguistic features.

Out of the corpus of studies in this review, 3 studies have yielded a better insight into relations between collaboration and interaction in oral task performances. There is evidence of a positive impact of peer-scaffolding strategies in conversations since the three studies reported an increase in LRE episodes, as well as better accuracy, vocabulary, and incorporation of linguistic terminology. The inclusion of multimedia-supported TBLT provided learners with further scaffolding strategies which had an impact on the incorporation of more vocabulary, and linguistic features in conversation.

\section{Effectiveness of a TBLT framework on holistic approach measures of the speaking skill}

It was found that in 21 studies there appeared a holistic view to measuring the speaking skill. These studies used a quasi-experimental design with a pretest-experiment-posttest approach, except for one study which used a qualitative approach with descriptive data focusing on words rather than statistics by Yuniarisda, H. (2014). In general, most studies reported gains in the means of experimental groups' posttests, with only one exception. After data analysis of results was conducted, it is inferred that the components that benefited more after the intervention were negotiation of meaning and conversation skills. Few studies reported gains in fluency and pronunciation. On the whole, the aspect that has been highlighted in the studies is the increase in students' involvement in oral production activities. The main drawbacks have been found to be the fact that in $70 \%$ of the studies a small sample was used, and the inclusion of measurements other variables such as self-efficacy and motivation. This fact presented a difficulty at the time of generalizing results which did not belong to this synthesis' research objectives.

At this stage, the studies which had a TBLT holistic intervention were chosen for metaanalysis as they provided sufficient data for contrast. Only 11 studies were selected for the meta-analysis out of 21 that made use of a TBLT lesson framework implementation. Reasons for exclusion of the 9 remaining studies were mainly due to: qualitative research design, within-subject design or insufficient data for effect size calculations in the reports.

To analyze the effects of TBLT interventions on oral production, studies that were selected had to compare an experimental group with a TBLT framework treatment versus a control group that received another condition. Studies that ultimately involved hypothesis testing of TBLT experimentation and reflected via posttest reports.

For quantitative pretest-experiment-posttest design studies that provided proper information of statistical tests, such as independent t-test or paired samples t-tests, on means and standard deviations, effect sizes were computed.

One of the between-group studies in this section, Kebede's (2021), was considered to be an outlier because the calculated Cohen's d effect value was 5.8, which represented a 
difference of more than 0.5 from the mean of the rest of studies. This meant that it constituted an outlying effect, and was thus removed.

\section{Quantitative Meta-analysis}

After the systematic coding analysis was effected, it was evident that a meta-analysis would enable the researcher to generalize the magnitude of effects in these TBLT strategy interventions. As well as compare the effects across studies, and thus, be able to answer more general questions than the ones presented in the studies within this research domain. Consequently, for this quantitative meta-analysis, the effect sizes of 11 unique sample studies were combined to determine an average effect of a TBLT holistic intervention. Table 3 summarizes the meta-analytic findings displaying population sizes and mean effects.

\section{Main effects of TBLT holistic interventional studies}

Table 3 summarizes the main effects for between-group studies that included a TBLT holistic measure. The main effect calculated, represented with the black diamond in figure 2 , determines a medium-large effect $d=0,78$.

\section{Table 3}

Summary of coded studies and effect sizes across TBLT Holistic Strategy quasiexperimental designs. Meta-Analysis Results (95\% Confidence Interval)

\begin{tabular}{|c|c|c|c|c|c|c|c|}
\hline \multicolumn{5}{|c|}{$95 \% \mathrm{CI}$} & \multicolumn{3}{|c|}{$95 \% \mathrm{CI}$} \\
\hline Label & $\begin{array}{c}\text { Cohen's } \\
\text { d }\end{array}$ & Lower & Upper & $\mathbf{p}$ & $\begin{array}{c}\text { Diamond } \\
\text { Ratio }\end{array}$ & Lower & Upper \\
\hline Overall & 0.781 & 0.561 & 1.00 & $<.001$ & 1.46 & 1.04 & 2.54 \\
\hline Studies & & Cohen's d & Lower & Upper & Total & N1(exp.) & $\begin{array}{c}\text { N2 } \\
\text { (ctrl.) }\end{array}$ \\
\hline Aliakbari, & & 0.553 & 0.0371 & 1.068 & 60 & 30 & 30 \\
\hline \multicolumn{8}{|c|}{ Jamalvandi, B. (2010) } \\
\hline Alsagheer, & \& & 1.120 & 0.4834 & 1.756 & 44 & 23 & 21 \\
\hline \multicolumn{8}{|c|}{ Hasan, A. (2014) } \\
\hline Aziz, A. (2 & & 0.554 & 0.0764 & 0.554 & 70 & 35 & 35 \\
\hline Chen, B. \& & & 1.385 & 0.8629 & 1.906 & 70 & 35 & 35 \\
\hline \multicolumn{8}{|c|}{ Zhang, Y. (2015) } \\
\hline El-Sadat, E & (2018) & 0.989 & 0.4926 & 1.485 & 70 & 35 & 35 \\
\hline Marzban, $A$ & & 0.168 & -0.2707 & 0.607 & 80 & 40 & 40 \\
\hline \multicolumn{8}{|c|}{ Hashemi, M. (2012) } \\
\hline Nita, A. et & (2019) & 1.179 & 0.4287 & 1.930 & 32 & 16 & 16 \\
\hline Rahmah, H & (2017) & 0.466 & 0.0472 & 0.885 & 90 & 45 & 45 \\
\hline
\end{tabular}




\section{Table 3}

Summary of coded studies and effect sizes across TBLT Holistic Strategy quasiexperimental designs. Meta-Analysis Results (95\% Confidence Interval) (continuation)

\begin{tabular}{lcccccc}
\hline Studies & Cohen's d & Lower & Upper & Total & N1(exp.) & $\begin{array}{c}\text { N2 } \\
\text { (ctrl.) }\end{array}$ \\
\hline $\begin{array}{l}\text { Santhosh, P. \& } \\
\text { Meenakshi, K. (2017) }\end{array}$ & 0.892 & 0.4590 & 1.326 & 90 & 45 & 45 \\
Mekala, S. (2017) & 0.633 & 0.1727 & 1.094 & 76 & 38 & 38 \\
Wahidin, I. (2016) & 1.083 & 0.4891 & 1.676 & 50 & 25 & 25 \\
\hline
\end{tabular}

Source: Meta-analysis results of studies with a TBLT holistic intervention

Developed by: The author

Figure 2

Forest plot showing effect sizes and confidence intervals for 11 experimental betweengroups studies

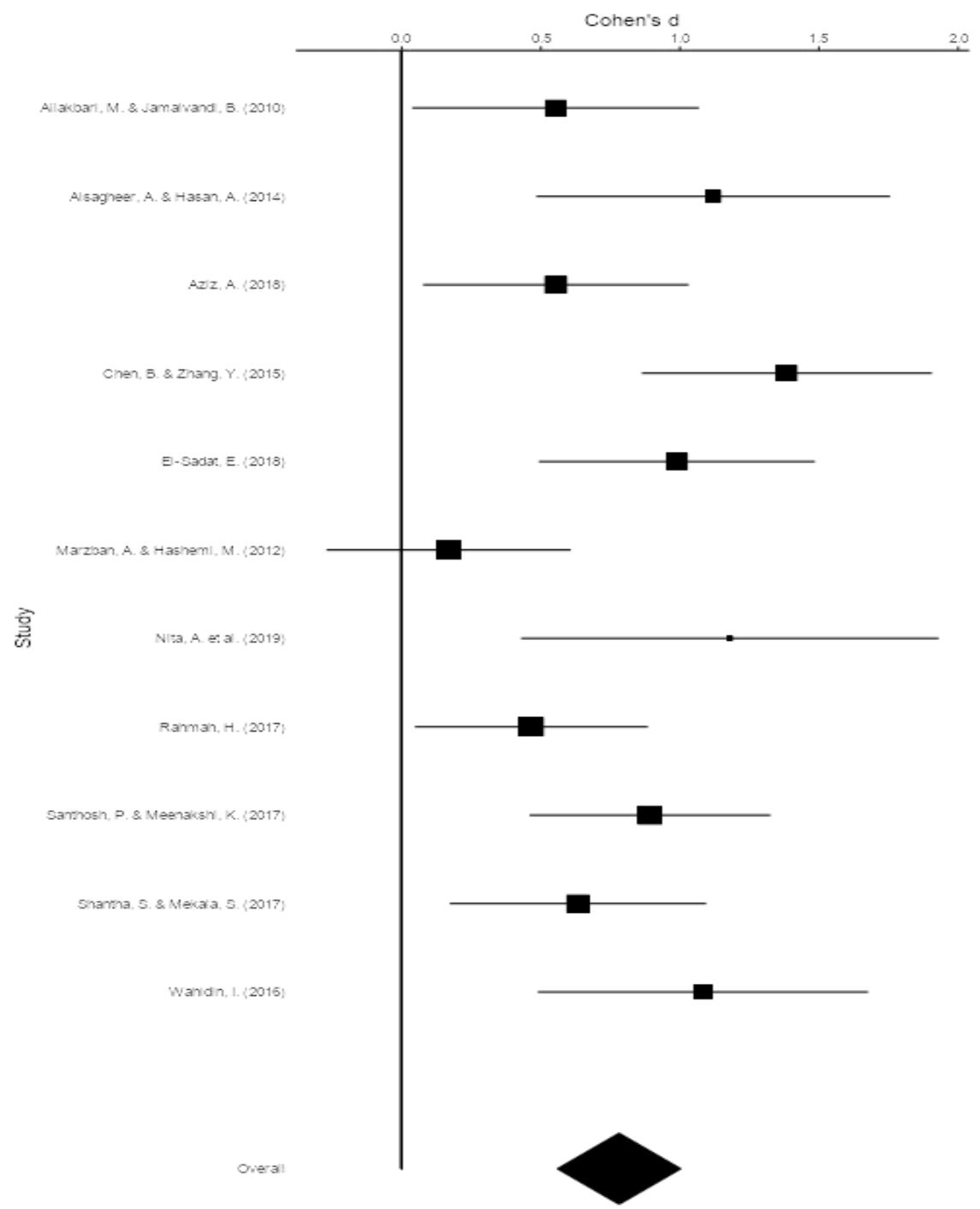

Source: Meta-analysis calculation of studies with a TBLT holistic intervention Developed by: The author 


\section{Discussion}

This synthesis examined several research designs and speaking constructs measures. In this section, a summary and discussion of the findings on this research synthesis and metaanalysis are presented. Some suggestions for further research directions are also given.

Research Question 1: What are the benefits and limitations of the implementation of pedagogical task frameworks in the development of spoken production constructs in terms of (a)complexity, (b) accuracy, (c) fluency, and (d) spoken interaction in these studies?

From the analysis, it can be stated that task repetition and task planning offer more gains for the enhancement of accuracy and complexity in oral production. Different task planning and task sequence treatments have a positive impact on fluency. One aspect that favors conversational skills and negotiation of meaning is scaffolding. It has been evidenced that peer-scaffolding and multimedia-supported TBLT strategies aid learners in gaining interactional skills as well as fluency in completing oral tasks. Due to the aforementioned reasons, it is significant to increase the number of studies that have scaffolding as treatment in order to corroborate its effects on conversational skills within a TBLT framework. This suggests that peer-scaffolding constitutes an effective strategy during a task cycle since it enhances interaction and negotiation of meaning. Also, the synthesis evidenced that repetition and rehearsal of the same task over a period of time creates a favorable development of the three CAF dimensions. In particular, the repetition of tasks within a time space favors the development of accuracy in spoken production as evidenced by Gashan \& Almohaisen's (2014) which used repetition of an informationgap task in a two-week time frame. In the case of studies that implemented accuracy measures, it should be said that the investigations that experimented with more complex and demanding tasks evidenced the occurrence of more interaction and attention to language forms. On the other hand, pre-task modelling and task rehearsal have been consolidated as key elements for accuracy gains in TBLT strategies since they allow learners to focus on their particular linguistic needs.

Research Question 2: Overall, how effective is a TBLT strategy for the development of the speaking skill for L2 learners in classroom environments?

In experimental and quasi-experimental studies, there is evidence for gains after treatment. Specifically, while the effects seem to vary across the studies included in the meta-analysis, 5 of these studies had a medium to large effect.

All in all, it has been evidenced that more classroom research is needed to assess the effects of TBLT in normal classroom conditions. Due to the fact that some studies were carried out in laboratory conditions and with a small sample, the impact of TBLT strategies across classroom longitudinal studies is needed. However, in most studies student engagement was increased, as well as the development of accuracy and fluency. Small gains have been evidenced for pronunciation. For further research, observations must be taken into account since in most studies it was unclear whether teachers had 
received preparation for TBLT implementation. The results from the meta-analysis of TBLT treatment effects also show slight variation with 4 studies having a medium size effect and the rest of the studies contributing large effects. A significantly large effect was computed in Chen, B. \& Zhang, Y. (2015) study where $\mathrm{d}=1.38$ which makes it larger than the rest. In this study the means form pretest to posttest had an increase of 21,71. Nonetheless, it can be considered a huge effect for only a 3-month intervention. Adding to this, it must be stated that the large effects appraised in the 4 studies had an intervention that lasted more than 2 months and more than 60 hours of instruction. Factors such as the emphasis on cooperative learning, learner engagement, motivation and group work seem to favor a larger effect in contrast to traditional teacher center approaches to the treatment of the speaking skill as documented in these studies.

\section{Conclusions}

- This study applied a synthetic approach to examine research on task-based L2

- learner oral production. The results of the synthesis and the meta-analysis are varied due to the number of independent variables of study reports that focused on CAF measures. Nonetheless, after the analysis-synthesis process was concluded, it has become clear that TBLT offer significant advantages for oral production enhancement. Especially, the implementation of task repetitions and pre-task planning seem to favor CAF constructs when applying a TBLT framework. This implies that tasks must be repeated for the improvement of conversational skills in the learners.

- It becomes evident that TBLT for the development of speaking skills is beneficial for intermediate students mostly. The meta-analysis part of this systematic review reveals a medium to large effect in between-groups designs. However, most studies included only a quantitative approach to measuring the impact of a TBLT treatment versus other conventional methods. Although it can be said that a TBLT framework is effective in developing speaking skills in the classroom, more randomized experiments are needed to avoid sampling bias.

- Due to the wide array of research designs employed for the measurement of CAF dimensions, more studies are needed for the meta-analysis of effects of task interventions on fluency, accuracy and linguistic complexity. Notwithstanding these kind of limitations, this synthesis of studies supports the implementation of task repetition and pre-task planning for the development of these dimensions in speaking activities within the L2 lesson. According to these results, a TBLT framework favors the enhancement of oral production in intermediate learners of different cultures and ages.

\section{References}

Ahmadian, J., (2011). The effects of 'massed' task repetitions on complexity, accuracy, and fluency: does it transfer to a new task? The Language Learning Journal 39(3): 269-280. http://dx.doi.org/10.1080/09571736.2010.545239 
Aliakbari, M., Jamalvandi, B. (2010)- The Impact of 'Role Play' on Fostering EFL Learners'Speaking Ability: A Task-Based Approach. Pan-Pacific Association of Applied Linguistics 14(1), 15-29.

Alsagheer, A., Hasan, A. (2014). The effect of using task-based learning in teaching English on the oral performance of the secondary school students. International Interdisciplinary Journal of Education 3(2). https://doi.org/10.12816/0003003

Aziz, A. (2018)-The effect of Task-based language teaching (TBLT) strategy on students' speaking ability in demonstrative speech. Journal of Linguistics and Language Teaching 4(2). http://dx.doi.org/10.29300/ling.v4i2.1665

Bygate, M., Samuda, V. (2005). Integrative planning through the use of task repetition. In R. Ellis, (Eds.), Planning and task performance in second language. (pp. 3774). Amsterdam: John Benjamins Publishing.

Chen, B., Zhang, Y. (2015). An Experimental Study on Task-Based Interaction in Improving College Students' English Speaking Ability. 2nd International Conference on Education Reform and Modern Management (ERMM 2015). www.atlantis-press.com

Dao, P., Iwashita, N., Gatbonton, E. (2016). Learner attention to form in ACCESS taskbased interaction. Language Teaching Research 21(4): 454-479. https://doi.org/ $10.1177 / 1362168816651462$

Ellis, R., Shintani N. (2014). Exploring Language Pedagogy through Second Language Acquisition Research. Routledge Introductions to Applied Linguistics.

El-Sadat, E. (2018). Improving speaking skills through task-based language teaching strategies. Egyptian Journals 105(4):37-46. https://doi.org/10.21608/maed.2019.140740

Gashan, A., Almohaisen, F. (2014)-The Effect of Task Repetition on Fluency and Accuracy of EFL Saudi Female Learner's Oral Performance. Advances in Language and Literary Studies 5(4). http://dx.doi.org/10.7575/aiac.alls.v.5n.3p.36

Hedges, L.V. (1981). Distribution Theory for Glass Estimator of Effect Size and Related Estimators. Journal of Educational Statistics 6(2): 101-128.

Heyvaert, M., Maes, B., Onghena, P. (2011). Mixed methods research synthesis: definition, framework, and potential. Springer Science+Business Media B.V. 2011. https://doi.org/10.1007/s11135-011-9538-6

Housen, A., Kuiken, F., Vedder, I. (2012). Dimensions of L2 performance and proficiency. John Benjamins Publishing Company. 
Housen, A., Kuiken F. (2009). Complexity, Accuracy and Fluency in Second Language Acquisition. Applied Linguistics 30(4): 461-473. https://doi.org/10.1093/applin/amp048

Kebede, M. S., (2021). The Effect of Task-Based Language Teaching on Developing

Students' Oral English Achievement: With Reference to Damot Preparatory School Grade Eleven Students. Journal of Literature, Languages and Linguistics. Vol 75. https://doi.org/10.7176/JLLL/75-03

Marzban, A., Hashemi, M. (2012). The impact of opinion-gap tasks on the speaking of Iranian intermediate EFL learners. Procedia-Social and Behavioral Sciences 70: 943-948. https://doi.org/10.1016/j.sbspro.2013.01.142

Nita A., Rozimela, Y., Ratmanida. The Influence of Task-based Language Teaching on Speaking Skill of EFL Students with Intrinsic Motivation. International Journal of Literature and Arts 7(6): 179-184. https://doi.org/10.11648/j.ijla.20190706.18

Norris, J. M., Ortega, L. (Eds.). (2006). Synthesizing research on language learning and teaching. John Benjamins Publishing Company.

Nunan, D. (2004). Task-based Language Teaching. Cambridge University Press.

Page, M.J., McKenzie, J.E., Bossuyt, P.M., Boutron, I., Hoffmann, T.C., Mulrow, C.D. The PRISMA 2020 statement: an updated guideline for reporting systematic reviews. BMJ 2021; 372: n71. https://doi.org/10.1136/bmj.n71

Pica, T., Young, R., Doughty, C. (1987). The impact of Interaction on Comprehension. Tesol Quaterly 21(4): 737-758. http://www.jstor.org/stable/3586992

Prabhu, N.S. (1987). Second Language Pedagogy. Oxford University Press.

Rahmah, H. (2017). The Effectiveness of Task-Based Language Teaching in

Developing Speaking Skills at SMKN 2 MALANG. PARADIGMA: Jurnal Filsafat, Sains, Teknologi, dan Sosial Budaya 23(1): 53-56. https://doi.org/10.33503/paradigma.v23i1.369

Richards, J., Rodgers, T. (2001). Approaches and Methods in Language Teaching. Cambridge University Press.

Santhosh, P., Meenakshi, K. (2017). Enhancing Oral Communication through Task Based Language Teaching among Polytechnic Students. Indian Journal of Science and Technology 10(11): 1-4. https://doi.org/10.17485/ijst/2017/v10i11/106481

Shantha, S., Mekala, S. (2017). The role of oral communicative tasks (OCT) in developing the spoken proficiency of engineering students. Advances in Language and Literary Studies 8(2). https://doi.org/10.7575/aiac.alls.v.8n.2p.161 
Skehan, P. (2009). Modelling Second Language Performance: Integrating Complexity, Accuracy, Fluency, and Lexis. Applied Linguistics 30(4): 510-532. https://doi.org/10.1093/applin/amp047

Van den Braden, K. (2006). Task-based Language Teaching, From Theory to Practice. Cambridge University Press. 


\section{PARA CITAR EL ARTÍCULO INDEXADO.}

Medina Fernández, A. (2021). The effects of Task-Based Language Teaching on the Speaking Skill: A systematic research synthesis and meta-analysis . Ciencia Digital, 5(4), 72-93. https://doi.org/10.33262/cienciadigital.v5i4.1801

\section{Ciencia \\ LDigital}

El artículo que se publica es de exclusiva responsabilidad de los autores y no necesariamente reflejan el pensamiento de la Revista Ciencia Digital.

El artículo queda en propiedad de la revista y, por tanto, su publicación parcial y/o total en otro medio tiene que ser autorizado por el director de la Revista Ciencia Digital.
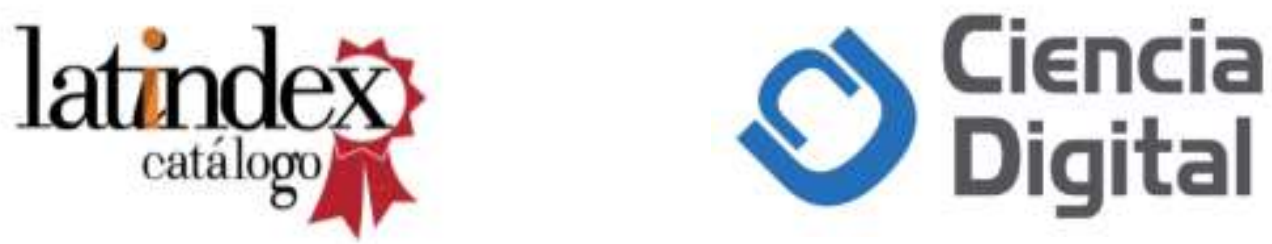